\title{
Structural Equation Model For The Relationship between Property Value and Public Transport Accessibility
}

\author{
Siti Nurlaela \\ Urban and Regional Planning Department, Faculty of Architecture, Design and Planning \\ Institut Teknologi Sepuluh Nopember \\ e-mail: sitnurlael0@gmail.com
}

\begin{abstract}
Abstrak - Property value capitalization has been part of spatialeconomic results of transportation infrastructure development. This paper presents a study to understand the relationship between property value and public transport accessibility. A structural equation model or SEM in terms of path analysis was developed and explained the backward-forward chain of sequential causality of property value, public transport accessibility and travel behavior. The backward chain explains the transportation influences land use in a sequential causality and the forward chain explains the relationship from land use to travel behavior. Path analysis reported the backward chain was only valid in a direct relationship from public transport accessibility to property value but failed to account for a sequential causality relationship from public transport accessibility, land use density/intensity and property value. The forward chain confirmed the significant relationship from accessibility to travel time and to the number of household trips through the influence of land use, however at low influence. Direct relationship from accessibility to travel behavior (car uses) mediating by travel distance was at moderate influence. Nevertheless, the paper reported the variances of property value explained by the overall LUTI relationship was only modes at $\mathbf{1 2 \%}$.
\end{abstract}

Kata Kunci- Land Use Development, Property Value, Public Transport Accessibility, Structural Equation Model (Path Analysis), Travel Behavior

\section{INTRODUCTION}

$\mathrm{S}$ TUDIES in property value capitalization related to the new transportation infrastructure development have been discussed from various perspectives. Property value concept has often been discussed as the appraisal or the price valuation of property or housing ([1], [2]). The concept of property valuation has been used in the calculation of the level of local tax assessment or value captured mechanisms ([3], [4] ). Another perspective of property value research is the analysis of public transport accessibility. The accessibility variable often been captured as part of the travel time saving that inherently accounted for in the determination of the house prices, in terms of location advantages ([5], [6], [7], [8], [9]). In addition, [10] discussed the role of house price in joint residential and work location choice. The improvement of public transport accessibility and land use development would create property value capitalization among other impacts, such as broader opportunities for activities and multimodal creation.

There were some degree of positive impacts of public transport extension on property value [11]. The strongest impact had emerged within a narrow radius from the transit node [12]. In line with these findings, [3] found that the Houston MetroRail transit line impacted positively on property value for residential properties located within a quarter mile of rail stops. Therefore, the connection between property value capitalization and travel patterns, whether it is direct or indirect, is an important part of the puzzle for better understanding land use and transport integration, yet it has rarely been discussed in the literature. Furthermore, [14] suggested that the incorporation of property value in the LUTI framework is very critical in order to achieve a better understanding of relationship between land use and transport. The property value capitalization as the travel time saving gained from the improved public transport accessibility [14].

This paper attempts to conduct an aggregate analysis to assess the relationship between the land use-transportation components accounts for the inclusion of property value variable. The relationship will be elaborated in a backward and forward chain of sequential causality between land use and transportation in the context of Perth - Mandurah railway line extension. The extended railway line Perth - Mandurah in Perth Metropolitan region was operated in December 2007. The railway line situated along a $72 \mathrm{~km}$ network from Perth to Mandurah, assumed to make a direct influence in land use and property development on its network coverage along the PerthMandurah network particularly, and on Perth Metropolitan region in general.

The relationship among LUTI components being hypothesized in this paper consisted of public transport accessibility (closeness centrality index, followed [15]); land use intensity in terms of total floor space, land use density in terms of development area, property value, travel patterns (travel time and travel distance) and some components of travel behavior such as the proportion of public transport and car uses, and the number of household trip daily. The socio-demographic variables were included in the analysis, consisted of family size, car ownership, and household income.

Further details on the relationship between public transport accessibility, property value, land use intensity/density and travel behavior measures were hypothesized as followed: public transport accessibility improvement - land use development and property value seems to have interrelations in a sequential but also recursive. Direct impacts of new transport project consist of the improvement of transit public transport 
accessibility, land use densification, and property value increases. These impacts create a backward chain in land usetransport system where transport influences land use component. In this regards, the capitalization of property value is as an indicator of travel time saving as explained in [14]. The individuals/households will consider these travel time savings due to an improvement in public transport accessibility to amenities, transport facilities, work place and schools, etc, as one of important factor influencing their residential location choice.

Land use development is assumed to change the distribution of activities, hence also influence the attractiveness of land use and destinations. These lead to the change in origins and destinations or travel patterns. These later processes called as the forward chain that explains how land use influences travel behavior in a sequential causality relationship. This paper examines the role of property value in both backward and forward chain causality relationship within the land use transportation interaction framework.

\section{METHOD}

Structure equation model is a powerful tool of to examine relationship/causality on a complex phenomena [16]. Path analysis is a special case of SEM with observed variable; whereas ordinary linear regression is also the special case of SEM with one observed endogenous variables and multiple observed exogenous variables. However, SEM measurement model is used to specify latent or unobserved variables as linear functions or weighted averages of other variables in the system. Other observed variables have a role of indicators of the latent constructs [17]. Further, covariance analysis in SEM is differentiated with the least square technique usually used in regression. The difference of SEM with path analysis or exploratory factor analysis, such as PCA or principal component analysis. In PCA, all elements of the matrix defining the latent variables, named as factors, in terms of linear combination of the observed variables take on non-zero values. These values, known as factor loadings, measure the correlations between the factors and the observed variables by maximizing the number of loadings with high and low absolute values [17]. In short, SEM can be described as a generalization, integration, and extension of these familiar models of linear models mentioned (regression, factor analysis, or PCA analysis) [18].

In this paper, SEM was used to examine the causality relationship, to specify the magnitude and direction of the relationship, and to separate between direct and indirect influences as specified in the research design. SEM was used to answer the research question: 'How much the changes in accessibility, land use, and property value due to public transport extension would influence the travel pattern or travel behavior of residents in the rail station precinct?'.

The technique of SEM as mentioned in [17] was used to capture the causal influence or regression effects from the exogenous variables on endogenous variables; and also the causal influence from the endogenous variables on other endogenous variables. SEM generally estimated using covariance structure analysis. Model parameters are determined such that the variances and covariance of the variables implied by the model are as close as possible with the observed variances and covariance of the sample. In the other way, SEM was used in order that the estimated parameters make the variance-covariance matrixes predicted by the model as similar as possible to the observed variance-covariance matrixes while respecting the constraints of the model. The model was able to handle a large amount of endogen and exogenous variables. The latent or unobserved variable was specified as linear combinations of the weighted average of the observed variables.

In the model identification, SEM differentiated the measurement model and the structural model. In model specification, SEM postulated the existence of direct effects between variables and optimal error term covariance of several types. Each postulated effect usually corresponds with a free parameter. Specification of the model involved designating the variables, relations among variables, and the status of parameters in the model [18]. In terms of measurement causality, [17] explained the important distinction in SEM in regards with some concept of causality, i.e.:

- Direct effect: direct effect measures the links between a productive variables and the variable that is the target of the effect. Each direct effect corresponds with the arrow in a path or flow diagram. SEM model is specified by defining which direct effects are present and which are absent. The direct effects embody the causal modelling in SEM.

- Indirect effect: indirect effect is the sum of all of the effects along the paths between the two variables that involve intervening variables.

- Total effect: total effect is the sum of direct effects and indirect effects. The total effects of the exogenous variables on the endogenous variables are sometimes known as the coefficients of the reduced form equations.

Path analysis in this paper discussed the general framework of LUTI to show the relationship between public transport accessibility, land use, property value and travel patterns/travel behavior in a form of backward and forward chain of sequential causality. Path analysis attempts to examine if the zero partial correlation $(\mathrm{r}=0)$ between $\mathrm{x}$ and $\mathrm{y}$, holding $\mathrm{z}$ constant, is actually a spurious correlation between $\mathrm{x}$ and $\mathrm{y}$ when $\mathrm{z}$ is actually a confounder or causally prior to $\mathrm{x}$ and $\mathrm{y}$. Other possible relationship is that, when $\mathrm{z}$ is causally prior to $\mathrm{x}$ and causally subsequent to $\mathrm{y}, \mathrm{z}$ is an intervening variable between $\mathrm{x}$ and y (Simon, as cited in [19]). This paper assumed that the property value was an intervening variable in the association between land use and transportation. This paper used SEM in the form of path analysis as this technique was able to identify the causality relationship while allowing the interchange position between independence and dependence variable in the structure of equation. Thus, the structure that was represented by path analysis allows for the examination of backward and forward chain of relationship in land use and transport components. 


\section{RESULTS AND DISCUSSION}

\section{A. Result}

Path analysis used sample size of 321 suburbs in Perth Metropolitan region. Some data had violated the assumption of normality distribution, i.e. land use measured by development area and total floor space area, travel distance, travel time, the proportion of public transport uses, proportion of car uses, property value, and the number of household trips. For this reason, the modification of model was required, i.e. by using the bootstrapping, a technique that is viewed to be more tolerant of non-normality [20]. Development of the criterion and the interpretation of the model fits in this paper referred to [21].

Path analysis examined the backward and forward chain of sequential relationship. The backward chain consisted of the relationship between public transport accessibility, land use, and property value. The squared multiple correlations showed that the total variance of property value being explained by public transport accessibility and household income was $12 \%$. The indirect relationship from public transport accessibility to property value through land use has not been significant. Direct relationship from public transport accessibility to property value showed the magnitude influence of $(-0.30) 2$ with the correct sign of relationship or 0.09 . Direct relationship from household income on property value was $(0.17) 2$, lower than that of influence from public transport accessibility or 0.0289 . However, the low value of the squared multiple correlation implies there were too many unobserved variables that influence property value that were failed to be captured by the model. Therefore, the backward relationship was only valid partially as shown by direct relationship from public transport accessibility to property value, but failed to accounted for sequential or chain causality from public transport accessibility and land use to property value.

On the other hand, path analysis explained the forward chain causality that assumed the relationship between public transport accessibility and property value to travel behavior, mediating by land use factors. Land use has been explained by two variables, i.e. development area and total floor space area. Of these two variables, the square multiple correlation showed the proportion of the variances that were accounted for by each of their predictors only high enough for the total floor space variable or FLSP. The variable of FLSP has 0.568 squared multiple correlation. This means, variable closeness centrality (accessibility), developed area, and family size has accounted for $56.8 \%$ of the variance of the total floor space. Public transport accessibility variable or closeness centrality was an exogenous variable.

The variables in questioned, i.e. travel behavior, consisted of the proportion of public transport uses, the proportion of car uses, and the number of household trips; and travel patterns in terms of travel time and travel distance. Of these variables, the total variance of household trips that being explained by the model was $49.7 \%$, travel time $42.9 \%$, travel distance $26 \%$, and the proportion of car uses $28.9 \%$. The model cannot explain the variance in the proportion of public transport uses, as its squared multiple correlation was too small, i.e. only $1.8 \%$. The number of household trip per day on average had been explained by travel time, travel distance, household income, family size, and vehicle ownership. Based on hypothesizes of the model, it was expected that there was an indirect effect from public transport accessibility variable on the number of trips mediated by travel time and travel distance. In addition, the indirect effect from public transport accessibility to travel time was mediated by land use besides its direct effect has also been as expected. The public transport accessibility had indeed influenced travel time and travel distance by $(-0.243) 2$ or 0.06 and $(0.510) 2$ or 0.26 . Public transport accessibility had influenced travel distance at a considerably medium degree 0.26 . However, the next sequence relationship, i.e. the influence of travel distance on the number of household trip was too low, i.e. $(-0.031) 2$ or $9 \%$ but stronger for car use, i.e. $29 \%$. In addition, the influence of public transport accessibility on land use was too weak, nevertheless both of land use variables had intervened the relationship from accessibility to the number of household trips through travel time. Therefore, the model confirmed the forward chain of causality relationship partially, i.e. from public transport accessibility directly to travel pattern and travel behavior, but the influence of causality of land use as mediating variable from accessibility to travel behavior was very weak. The improved public transport accessibility played an important role in influencing travel distance then to car use proportion but no intervening effect from any of land use variables. This means, the effect of public transport accessibility to travel behavior intervening by land use variables and travel pattern was only partially true.

In regards with household attributes, it seems that household income and household size has influenced the number of household trip more than that of the variables hypothesized by the model, such as public transport accessibility and land use. Household income influenced as much as $25 \%$ and household size $14 \%$. It suggested that the influence of household characteristics on trip number was stronger than that of land use variables and public transport accessibility.

This paper discussed some of the fit indices, i.e. the absolute fit index (chi-square, X2/df, GFI, AGFI, RMSEA) and some comparative fit index (TLI, CFI and RMR).The overall model fit tested by chi-square. Chi square tested the null hypothesis, i.e. the model being tested fits no worse than a saturated model. Saturated model is the model with zero chi-square and zero degree of freedom (it fits perfectly with the data).

The fit indices from SEM output in this model (as shown in table 2) showed that overall goodness of fit mentioned by chisquare was significant or $p>0.05$. This means that the model had perfect fit in the population was true, i.e. the discrepancy between the matrix of implied variances and covariances in the model and the matrix of empirical sample variances and covariances was due to chance alone and concluded that the model fitted representation of the data (the discrepancy was very small). The ratio of chi-square and degree of freedom $(\mathrm{X} 2 / \mathrm{df})$ suggested the value of greater than 1 or less than 2 as indication of a good fit. The model showed this value was 1.78 indicated a good fit Testing the null hypothesis with BollenStine bootstrap result in p-value 0.164 indicated this value was 
above 0.05 which was significant. The value of RMSEA is a derivation from chi-square. The RMSEA is a badness of fit index where the value declining with improving fit. The RMSEA is a measure of the discrepancy per degree of freedom, having first diminished the discrepancy function somewhat as a function of sample size. The RMSEA is bounded at a lower value of zero, but has no theoretically maximum value. A model with an RMSEA of 0.10 is unworthy of serious consideration[22]. A value of RMSEA of 0.05 or less indicates a close fit, suggesting that the model is tenable [22]. The model develops in this paper showed the RMSEA value was 0.049 with the lower limit 0.030 (less than 0.05) and upper limit 0.068 (less than 0.08 or 0.10 ). This means the model closely fit the data was retained. This has been supported by the value of PCLOSE 0.495 greater than 0.05 to accept the test of close fit.

The residual test was carried by the Root Mean-square Residual (RMR), similar to the Unweighted Least Squares discrepancy function as in the chi-square test. The RMR was the measure of the average difference or residual between the two matrices per elemen of the variance-covariance matrix. The incremental fit indices measure how much better the fitted model is compare to the baseline model or the independence model. This test was shown for example by the value of GFI or the Goodness of Fit Indes and the TLI or the Tucker-Lweis Index, the Comparative Fit Index or CFI. All these values should be greater than 0.95 . This paper carried these tests and the results reported the value of GFI 0.965 , TLI 0.957 and 0.974 represented the model was better than the independence or the null model.

Overall goodness fit of indices in the model (the fit statistic, residual, and the incremental index) reported the acceptable level. Although the model showed some issues in terms of normality and the sample size of data, the bootstrap method has effectively improved the model fit.

Table 1.

Standardized Regression Weights and Squared Multiple Correlations: (Group

\begin{tabular}{|c|c|c|c|c|c|}
\hline$\underline{\text { Standarized Re }}$ & gression & eights & $\begin{array}{r}\text { Estimat } \\
\mathrm{e} \\
\end{array}$ & $\begin{array}{l}\text { Squared } \\
\text { Multiple } \\
\text { Correlations }\end{array}$ & Estimate \\
\hline $\begin{array}{l}\text { Development } \\
\text { area }\end{array}$ & $<---$ & Accessibility & -.087 & $\begin{array}{l}\text { Development } \\
\text { area }\end{array}$ & .008 \\
\hline Distance & $<--$ & $\begin{array}{l}\text { Accessibilit } \\
\text { y }\end{array}$ & .510 & $\begin{array}{l}\text { Land use } \\
\text { intensity }\end{array}$ & .568 \\
\hline $\begin{array}{l}\text { Land use } \\
\text { intensity }\end{array}$ & $<---$ & $\begin{array}{l}\text { Accessibilit } \\
\text { y }\end{array}$ & -.110 & Distance & .260 \\
\hline $\begin{array}{l}\text { Land use } \\
\text { intensity }\end{array}$ & $<---$ & $\begin{array}{l}\text { Developme } \\
\text { nt area }\end{array}$ & .724 & Travel time & .429 \\
\hline $\begin{array}{l}\text { Land use } \\
\text { intensity }\end{array}$ & $<--$ & Family size & -.133 & $\begin{array}{l}\% \text { Public } \\
\text { transport use }\end{array}$ & .018 \\
\hline Travel time & $<---$ & $\begin{array}{l}\text { Accessibilit } \\
\mathrm{y}\end{array}$ & -.243 & Property value & .120 \\
\hline Travel time & $<---$ & $\begin{array}{l}\text { Developme } \\
\text { nt area }\end{array}$ & .062 & $\%$ Car use & .289 \\
\hline
\end{tabular}

\begin{tabular}{|c|c|c|c|c|}
\hline Travel time & $<---$ & Distance & .743 & Hhtrips \\
\hline Travel time & $<---$ & $\begin{array}{l}\text { Land use } \\
\text { intensity }\end{array}$ & -.026 & \\
\hline $\begin{array}{l}\% \text { public } \\
\text { transport }\end{array}$ & $<---$ & $\begin{array}{l}\text { Family } \\
\text { income }\end{array}$ & -.041 & \\
\hline $\begin{array}{l}\% \text { public } \\
\text { transport }\end{array}$ & $<---$ & Travel time & .129 & \\
\hline Hhtrips & <--- & Family size & .384 & \\
\hline Hhtrips & $<--$ & $\begin{array}{l}\text { Car } \\
\text { ownership }\end{array}$ & -.115 & \\
\hline$\%$ car use & $<---$ & $\begin{array}{l}\text { Family } \\
\text { income }\end{array}$ & .019 & \\
\hline Hhtrips & $<---$ & Travel time & -.141 & \\
\hline Property value & $<--$ & $\begin{array}{l}\text { Accessibilit } \\
\mathrm{y}\end{array}$ & -.301 & \\
\hline$\%$ car & $<--$ & Family size & .104 & \\
\hline$\%$ car & $<--$ & Distance & .239 & \\
\hline$\%$ car & $<--$ & $\begin{array}{l}\text { Car } \\
\text { ownership }\end{array}$ & .053 & \\
\hline$\%$ car & $<--$ & $\begin{array}{l}\% \text { public } \\
\text { transport }\end{array}$ & -.473 & \\
\hline $\begin{array}{l}\text { Property } \\
\text { Value }\end{array}$ & $<---$ & $\begin{array}{l}\text { Family } \\
\text { income }\end{array}$ & .171 & \\
\hline Hhtrips & $<---$ & $\begin{array}{l}\text { Family } \\
\text { income }\end{array}$ & .485 & \\
\hline Hhtrips & $<--$ & Distance & -.031 & \\
\hline
\end{tabular}

Table 2.

Model Fits Summary

RMR

\begin{tabular}{lcccc}
\hline \hline Model & RMR & GFI & AGFI & PGFI \\
\hline Default model & .650 & .965 & .932 & .495 \\
\hline Saturated model & .000 & 1.000 & & \\
\hline Independence model & 11.579 & .608 & .537 & .515 \\
\hline \hline
\end{tabular}

Baseline Comparisons

\begin{tabular}{lrrrrr}
\hline \hline Model & $\begin{array}{r}\text { NFI } \\
\text { Delta1 }\end{array}$ & $\begin{array}{r}\text { RFI } \\
\text { rho1 }\end{array}$ & $\begin{array}{r}\text { IFI } \\
\text { Delta2 }\end{array}$ & $\begin{array}{r}\text { TLI } \\
\text { rho2 }\end{array}$ & CFI \\
\hline Default model & .944 & .907 & .975 & .957 & .974 \\
\hline Saturated model & 1.000 & & 1.000 & & 1.000 \\
\hline Independence model & .000 & .000 & .000 & .000 & .000 \\
\hline \hline
\end{tabular}




\section{RMSEA}

\begin{tabular}{|c|c|c|c|c|}
\hline Model & RMSEA & LO 90 & HI 90 & PCLOSE \\
\hline Default model & .049 & .030 & .068 & .495 \\
\hline Independence model & .239 & .227 & .250 & .000 \\
\hline Description: & \multicolumn{4}{|l|}{ Symbol of arrows meaning } \\
\hline$\longrightarrow$ & \multicolumn{4}{|c|}{$\begin{array}{l}\text { Causality relationship is hypothesized and it is } \\
\text { found to be significant }\end{array}$} \\
\hline$------->$ & \multicolumn{4}{|c|}{$\begin{array}{l}\text { Causality relationship is hypothesized but it is } \\
\text { found to be not significant }\end{array}$} \\
\hline$-\cdot-\cdot->$ & \multicolumn{4}{|c|}{$\begin{array}{l}\text { Causality relationship is not hypothesized but it is } \\
\text { found to be significant }\end{array}$} \\
\hline
\end{tabular}

\section{B. Discussion}

The main contribution of this paper is the inclusion of the property value concept in the overall land use-transportation interaction framework (the LUTI). The property value concept has been discussed in the context the LUTI framework in terms of the co-location hypothesis. For example, the interplay behavior on choice of residential location and workplace location involving some trade off on wages, housing prices, and commuting costs [10]. Most literatures on property value concept discussed the hedonic regression model for predicting the property value, or factors affecting the price of land or property and the property valuation methods.

This paper hypothesized the property value concept as the intervening or mediating variable in the relationship between public transport accessibility and travel behavior. By path analysis or SEM model, the role of property value in the set of relationship between any components in LUTI has been clearer as seen by the model diagram (path) in terms of sequential causality. The introduction of forward and backward chain in the model is intend to offer a comprehensive perspective of LUTI, that is, the property value is not in an isolated concept when discussing the determinant factor of travel behavior. Indeed, most of literature remained at discussing the backward chain such as the relationship between the increase of public transport accessibility due to the development of new infrastructure to the change in property value (see [8], [11]). There has been an omission in the relation between the backward and the forward chain, i.e. the influence of the accessibility improvement post the transportation development would also affect the property value and land use development, hence, affect travel behavior.

There were some interesting findings reported from this paper. For example, this paper found the household income explained the variance of property value at some degree, in which the influence of household income on property value was only modes at 3\%. [6] emphasized the role of household income (or expense) determining the demand of housing in terms of size and tenure. This implied the distribution of housing by size and tenure (which often defined by its property value) would dictate the distribution of household by its demographic profile. This finding may support the new hypothesis that may be worth noting for the future research. That is, there may be indirect relationship between property value and travel behavior (the number of household trips and the mode choice) that are mediated by the variable of household income through the distribution location of property dictating the residential location choice and mode choice. On the other hand, the hypothesized relationship that the indirect relationship from public transport accessibility to property value intervening by land use variables has been supported partially. This finding was in agreement with the insight from [14] and [23] that mentioning the relationship between property value and land use through the concept of travel time savings. However, the relationship from accessibility to property value found in this paper came as a backward chain, and from accessibility to land use (development area and floor space area) as a forward chain in the relationship, but no direct or indirect relationship from property value to land uses.

Research finding revealed both the backward and forward chain of causality relationship was significant partially. Nevertheless, direct and indirect relationship from the accessibility to travel distance and travel behavior remained moderate. This paper found travel characteristics such as travel time and travel distance was actually intervening (mediated) the relationship between accessibility and land use to travel behavior (mode choice and trip number). Finding from this paper may be relevant with both the classical and modern literatures, for example as found in [24] and [25]. The backward and forward chain of sequential causality may imply the two way relationship in LUTI, that is the transport development will influence urban pattern and (residential) location [25], and that the urban pattern affect the available choice of transportation in turn [24].

\section{CONCLUSION}

Path analysis or SEM model developed in this paper contributed to explain the role of property value in the set of relationship in the LUTI framework. The property value concept related directly with the improvement of accessibility post the public transport extension. Path analysis explained the set of relationship clearer in terms of sequential causality. However, this paper reported relationship from accessibility to property value emerged as a backward chain, and from accessibility to land use (development area and floor space area) as a forward chain in the relationship, and no direct or indirect relationship from property value to land uses. These findings implied the worthiness of SEM technique as a more powerful tool to reveal a complex relationship attached to the LUTI framework.

\section{DAFTAR PUSTAKA}

[1] Watkins, C. (1999). Property valuation and the structure of urban housing markets. Journal of property investment and finance, 17(2), 157-175.

[2] Straszheim, M. (1974). Hedonic Estimation of Housing Market Prices: A Further Comment. The review of economics and statistics, 56(3), 404406.

[3] Pagourtzi, E. (2003). Real estate appraisal: a review of valuation methods. Journal of property investment and finance, 21(4), 383-401.

[4] McIntosh, J., Newman, P., Crane, T., \& Mourtiz, M. (2011). Discussion paper - Alternative Funding Mechanisms for Public Transport in Perth: The Potential Role of Value Capture. Perth: Curtin University Sustainability Policy Institute, Corview Group and Committee for Perth Retrieved From http://www.committeeforperth.com .au/pdf/Advocacy/Report\%20-\%20AlternativeFundingforPublicT ransportinPerthDecember2011.pdf 
[5] Buxton, M., \& Taylor, E. (2010). Urban Land Supply, Governance and the Pricing of Land. Urban Policy and Research, 29(01), 5-22.

[6] Cho, S.-H., Poudyal, N., \& Lambert, D. M. (2008). Estimating spatially varying effects of urban growth boundaries on land development and land value. Land Use Policy, 25(3), 320-329. doi: DOI: 10.1016/j.landusepol.2007.08.004

[7] Kryvobokov, M. (2007). Analysing location attributes with a hedonic model for apartment prices in Donetsk, Ukraine.(Report). International journal of strategic property management, 11(3), 157.

[8] Du, H., \& Mulley, C. (2007). The short-term land value impacts of urban rail transit: Quantitative evidence from Sunderland, UK. Land Use Policy, 24(1), 223-233. doi: DOI: 10.1016/j.landusepol.2005.12.003

[9] Rodríguez, D. A., \& Mojica, C. H. (2009). Capitalization of BRT network expansions effects into prices of non-expansion areas. Transportation Research Part A: Policy and Practice, 43(5),560-571. doi: DOI: 10.1016/j.tra.2009.02.003

[10] So, K. (2001). The Effects of Housing Prices, Wages, and Commuting Time on Joint Residential and Job Location Choices. American journal of agricultural economics, 83(4), 1036-1048.

[11] Cervero, R., \& Landis, J. (1997). Twenty years of the Bay Area Rapid Transit system: Land use and development impacts. Transportation Research Part A: Policy and Practice, 31(4), 309-333.

[12] Munoz-Raskin, R. (2010). Walking accessibility to bus rapid transit: Does it affect property values? The case of Bogotá, Colombia. Transport Policy, 17(2), 72-84. doi: DOI: 10.1016/j.tranpol.2009.11.002

[13] Pan, Q. (2012). The impacts of an urban light rail system on residential property values: a case study of the Houston METRORail transit line. Transportation Planning and Technology, 36(2), 145-169. doi: http://www.tandfonline.com/action /showCitFormats?doi=10.1080/030 81060.2012.739311.

[14] Ryan, S. (1999). Prooperty Values and Transportation Facilities: Finding the Transportation-Land Use Connection. Journal of Planning Literature, 13(4), 412-427.

[15] Curtis, C., \& Scheurer, J. (2010). Planning for sustainable accessibility: Developing tools to aid discussion and decision-making. Progress in Planning, 74(2), 53-106. doi: DOI: 10.1016/j.progress.2010.05.001.

[16] Van Acker, V., Witlox, F., \& Van Wee, B. (2007). The Effects of the Land Use System on Travel Behavior: A Structural Equation Modeling Approach. Transportation Planning \& Technology, 30(4), 331-353. doi: 10.1080/03081060701461675

[17] Golob,T.F. (2003). Structural equation modeling for travel behavior research. Transportation Resarch Part B, 37, 1 - 25.

[18] Hoyle, R. H. (Ed.), (2012), "Handbook of structural equation modeling", New York: Guilford Press

[19] Matsueda, R. L. (2012). Key Advances in the History of Structural Equation Modeling. In R. H. Hoyle (Ed.), Handbook of structural equation modeling (pp. 17-42). New York: The Guildford Press.

[20] Hancock, G. R., \& Liu, M. (2012). Bootstrapping Standard Errors and Data-Model Fit Statistics in Structural Equation Modeling. In R. H. Hoyle (Ed.), Handbook of structural equation modeling (pp. 296-306). New York: The Guiford Press.

[21] West, S. G., Taylor, A. B., \& Wu, W. (2012). Model Fit and Model Selection in Structural Equation Modeling. In R. H. Hoyle (Ed.), Handbook of structural equation modeling (pp. 209-231). New York: The Guilford Press.

[22] Browne, M.W., Cudeck, R., 1993. Alternative ways of assessing model fit. In: Bollen, K.A., Long, J.S. (Eds.), Testing Structural Equation Models. Sage, New Park, CA, pp. 136-162.

[23] Cervero, R., \& Kang, C. D. (2011). Bus rapid transit impacts on land uses and land values in Seoul, Korea. Transport Policy, 18(1), 102-116. doi: DOI: $10.1016 /$ j.tranpol.2010.06.005

[24] Hall, P. (1969). Transportation. Urban Studies, 6(3), 408-435. doi: $10.1080 / 00420986920080511$

[25] Waddell, P., Ulfarsson, G. F., Franklin, J. P., \& Lobb, J. (2007). Incorporating land use in metropolitan transportation planning. Transportation Research Part A: Policy and Practice, 41(5), 382-410. doi: DOI:10.1016/j.tra.2006.09.008. 